\title{
PERANCANGAN INFRASTRUKTUR JARINGAN RTRW.NET DESA GERINGING BARU DENGAN CENTRAL UNIVERSITAS ISLAM KUANTAN SINGINGI
}

\author{
M.Hasim Siregar ${ }^{1}$, Helpi Nopriadi ${ }^{2}$, Sri Chairani $^{3}$ \\ ${ }^{1,2,3}$ Fakultas Teknik, Program Studi Teknik Informatika, Universitas Islam Kuantan Singingi, \\ Jl. Gatot Subroto km.7 Kebun Nenas, Teluk kUantan, Kuantan Singingi - Riau, 29511 \\ e-mail :hasyimsiregar92@gmail.com
}

\begin{abstract}
ABSTRAK
Infrastruktur langit yang sedang dikembangkan saat ini belum merata hingga ke daerah terpencil dan belum tersedianya internet service provider dan jaringan internet. Selain itu tingkat daya beli masyarakat dalam membeli paket internet disuatu daerah terpencil sangat sulit tersebut membuat masyarakat tidak menggunakan akses internet. Dengan adanya pembangunan jaringan internet dengan konsep RTRW.NET adalah solusi untuk memberikan layanan jaringan internet dengan biaya yang murah sehingga masyarakat tersebut lebih mudah dan cepat mengakses informasi melalui internet, masyarakat desa tersebut dapat melakukan kegiatan-kegiatan yang memanfaatkan penggunaan teknologi informasi dalam aktifitasnya. Perancangan Infrastruktur Jaringan RTRW.NET Desa Geringging Baru Dengan Central Server Universitas Islam Kuantan Singingi (UNIKS) dibutuhkan perangkat jaringan koneksi nirkabel, UNIKS sebagaipenyedia layanan internet didesa Geringging Baru yang nantinya dipusatkan di balai desa. Dalam perancangan meliputi perangkat yang digunakan dalam membangun jaringan RTRW.NET mulai dari hardware, software dan instalasi alat serta perancangan topology yang akan digunakan dalam perancangan.
\end{abstract}

Kata Kunci: RTRW.NET, infrastruktur langit, internet, wireless, server.

\begin{abstract}
The sky infrastructure that is currently being developed is not evenly distributed to remote areas and there is no internet service provider and internet network available. In addition, the level of purchasing power of the community in buying an internet package in a remote area is very difficult, making it difficult for people to use internet access. With the development of an internet network with the concept of RTRW.NET is a solution to provide internet network services at a low cost so that the community can more easily and quickly access information via the internet, the village community can carry out activities that take advantage of the use of information technology in their activities. Designing Geringging Baru RTRW.NET Network Infrastructure With the Central Server of the Kuantan Singingi Islamic University (UNIKS) a wireless connection network device is needed, UNIKS as an internet service provider in Geringging Baru village which will be centered in the village hall. The design includes the tools used in building the RTRW.NET network starting from hardware, software and installation of tools as well as topology design that will be used in the design.
\end{abstract}

Keywords: RTRW.NET, infrastructure of sky, expensive internet, metropolitan area network, server.

\section{PENDAHULUAN}

Pada dasarnya pengetahuan akan teknologi informasi sudah menjadi kebutuhan primer seseorang karena seiring perkembangan industri telekomunikasi yang semakin berkembang pesat dan hal ini dikarenakan hampir sebagian besar kegiatan sehari-hari seseorang melibatkan bantuan teknologi informasi (internet) 
I N F O R M A I I A

Jurnal Informatika, Manajemen dan Komputer, Vol. 13, No. 1 , Mei 2021

eISSN : 2580-3042

pISSN : 1979-0694

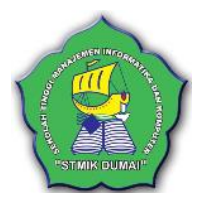

baik kegiatan belajar mengajar, bekerja di instansi maupun berwirausaha. Selain itu juga pengetahuan akan teknologi informasi merupakan modal utama seseorang untuk dapat bersaing di era globalisasi dan kemajuan zaman yang akan datang. Kemajuan teknologi juga dapat dilihat dari perkembangan internet yang membuat kita seakan-akan mampu melihat seluruh isi dunia. Jarak tak lagi jadi penghalang dalam komunikasi. Kulturisasi budaya dan pertukaran nilai-nilai dari tiap bangsa semakin cepat menyebar.

Pada desa Geringging Baru belum ada masuknya penyedia layanan internet kabel dan sulitnya mendapatkan sinyal selular sehingga untuk melakukan koneksi internet terasa lambat dan tidak stabil, masyarakat sekitar terutama yang masih sekolahan merasa kesulitan dan sulitnya akses internet dalam mengerjakan tugas dan menggali informasi-informasi pengetahuan mereka dari dunia luar. Masyarakat desa juga dapat keuntungan melalui pembelajaran online dan pemasaran produk-produk hasil olahan masyarakat secara online (e-commerce) sehingga dapat menambah promosi lebih luas dan turut mendukung program Presiden Republik Indonesia dalam pemanfaatan infrastruktur internet sampai ke pelosok desa sesuai dengan perkembangan revolusi industri 4.0

Dengan adanya pembangunan jaringan internet RTRW.NET ini adalah jalan keluar untuk memberikan layanan jaringan internet dengan biaya yang murah dan stabil sehingga masyarakat tersebut dapat lebih mudah dan cepat mengakses informasi melaui internet serta masyarakat desa tersebut dapat melakukan kegiatan-kegiatan yang memanfaatkan penggunaan teknologi informasi dalam aktifitasnya. RTRW.NET adalah jaringan komputer swadaya masyarakat dalam ruang lingkup RT/RW melalui media kabel atau wireless 2,4 Ghz dan hotspot sebagai sarana komunikasi rakyat yang bebas dari Undang Undang dan birokrasi pemerintahan (Nurcahya \& Internet, 2020). Perancangan Infrastruktur Jaringan RTRW.NET Desa Gringging Baru Dengan Central Server Universitas Islam Kuantan Singingi (UNIKS) dibutuhkan alat/perangkat jaringan jaringan Metropolitan Area Network koneksi nirkabel, UNIKS sebagai central server atau penyedia layanan internet yang memberikan bandwith ke desa Geringging Baru yang nantinya dipusatkan di balai desa Geringging Baru. Dalam perancangan meliputi perangkat yang digunakan dalam membangun jaringan RTRW.NET mulai dari hardware,

software dan instalasi alat serta perancangan topology yang akan digunakan dalam perancangan.

Dari permasalahan tersebut melalui pengabdian kepada masyarakat, peneliti membuat "Perancangan Infrastruktur Jaringan RTRW.NET Desa Gringing Baru Dengan Central Server Universitas Islam Kuantan Singingi” sehingga nantinya apabila di implementasikan pada Desa Geringging Baru dapat dimanfaatkan sepenuhnya untuk masyarakat desa tersebut dengan menggunakan internet murah dan stabil dengan membangun Hotspot WIFI pada balai desa tersebut, sehingga masyarakat Desa Geringging Baru tidak ada lagi yang tidak menggunakan internet untuk pembelajaran dan usahanya. Penelitian ini dilakukan dengan metode Pengumpulan data dan melakukan simulasi data,Bagian pendahuluan terdiri dari Latar belakangmasalah, tujuan, tinjauan pustaka yang komprehensif dan teori.

\section{a. Definisi Jaringan RTRW.Net}

Dari hasil jurnal (Pratama et al., 2018) bahwasannya RT/RW-Net suatu metode terdapat beberapa perangkat komunikasi dan komputer dalam suatu wilayah yang dapat saling berkomunikasi dan dapat berbagi data serta informasi. Konsep lain dari RT/RW-Net adalah memberdayakan pemakaian internet secara bersama-sama dengan pembayaran bersama sehingga jauh lebih murah

\section{b. .Definisi Point-to-Point}

Pointing to Point Point to point merupakan kondisi sambungan langsung dimana terdapat dua node yang saling terhubung tanpa perantara atau tanpa melibatkan node lain. Jaringan point to point dapat menghubung dua jalur LAN melalui mode bridge tanpa melalui proses routing. Antena jenis directional merupakan antena yang cocok untuk pemasangan point to point karena memiliki pancaran yang lurus dan tidak menyebar (Sururi, 2018).

\section{c. Wireless Radio}

WMAN (Wireless Metropolitan Area Network), Teknologi ini mengizinkan koneksi dari berbagai jaringan dalam suatu area metropolitan seperti bangunan-bangunan yang berbeda dalam suatu kota, yang mana dapat menjadi alternatif atau cadangan untuk memasang kabel tembaga atau fiber (Darmawan \& Marlinda, 2015). 
I N F O R M A I I A

Jurnal Informatika, Manajemen dan Komputer, Vol. 13, No. 1 , Mei 2021

eISSN : 2580-3042

pISSN : 1979-0694

\section{d. Mikrotik}

Mikrotik berfungsi untuk memantau koneksi dalam suatu jaringan komputer. (Sumardi \& Zaen, 2018) Mikrotik merupakan vendor yang menyediakan sistem operasi maupun hardware yang berguna dalam membangun sebuah router yang handal. Mikrotik RouterOS ${ }^{\mathrm{TM}}$ adalah sistem operasi dan perangkat lunak yang dapat digunakan untuk menjadikan komputer manjadi router network yang handal, mencakup berbagai fitur yang dibuat untuk ip network dan jaringan wireless, cocok digunakan oleh ISP dan provider hotspot.

\section{e. Mikrotik RouterOS ${ }^{\mathrm{TM}}$}

Mikrotik RouterOSTM Adalah versi MikroTik dalam bentuk perangkat lunak yang dapat diinstal pada komputer rumahan (PC) melalui CD. File image MikroTik RouterOS dapat diunduh dari website resmi MikroTik (Sumardi \& Zaen, 2018).

\section{METODELOGI PENELITIAN}

\section{a. Rancangan Penelitian}

Penelitian ini dilaksanakan pada desa

Geringging Baru Kabupaten Kuantan Singingi dengan Metode pengumpulan data dilakukan sebagai berikut :

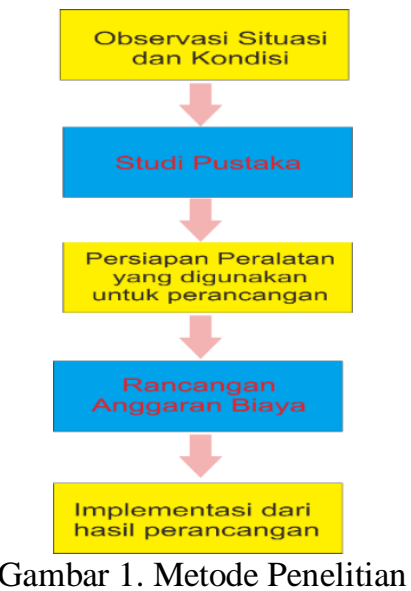

\section{b. Observasi Situasi dan Kondisi}

Dalam tahapan ini peneliti melakukan observasi ke lokasi penelitian dan melakukan simulasi menggunakan aplikasi simulasi jaringan nirkabel dengan menggunakan "AirLink". Aplikasi simulasi ini digunakan secara online yang dibuat oleh perusahaan "Ubiquiti networks Inc." Dari aplikasi ini kita dapat melihat jarak antara central server dengan desa geringging baru, gangguan akibat pohon/gedung dan bukit daerah tersebut serta mampu memprediksi

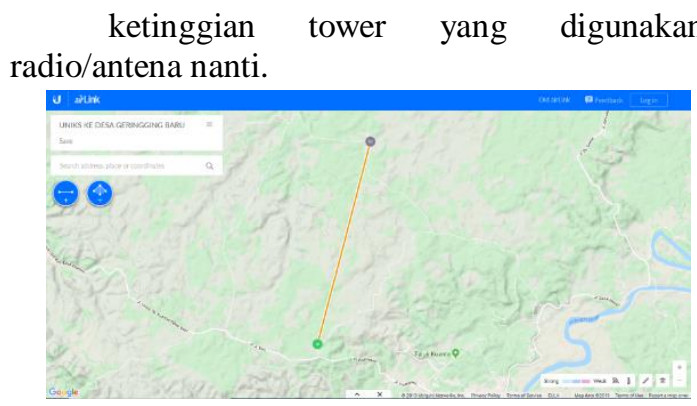

Gambar 2. Jarak dari Server ke Desa

\section{c. Studi Pustaka}

Pada tahapan ini peneliti menggunakan berbagai referensi dari buku literatur dan jurnaljurnal ilmiah yang resmi yang sesuai dengan penelitian ini serta dari hasil simulasi yang dilakukan.

\section{d. Persiapan Peralatan Jaringan}

Dalam membangun jaringan RTRW.NET Antena merupakan perangkat penting yang ada pada setiap sistem telekomunikasi dan komunikasi, tidak ada sistem jaringan wireless yang tidak memiliki antena. Pemilihan antena yang sesuai dengan kebutuhan dan perancangan ketinggian tower dan pemasangan yang benar akan menjamin kelancaran pengiriman bandwith yang maksimal

\section{e. Rancangan Anggaran Biaya (RAB)}

Pada tahap ini peneliti mengidentifikasi rancangan anggaran biaya-biaya yang dibutuhkan dalam membangun infrastruktur jaringan RTRW.NET dari Central Server ke desa Geringging Baru

f. Pengembangan Sistem

Pada tahapan ini peneliti menggunakan metode pengembangan Metode analisis dan perancangan menggunakan Network Development Life Cycle (NDLC) dengan pendekatan Top Down Approach. Perancangan intranet untuk mendukung proses pembelajaran masih berupa Prototype. Tahapan Network Development Life Cycle (NDLC) mencakup tahapan: a) Analisis, menganalisis kebutuhan untuk melakukan penelitian, permasalahan yang ada, topologi jaringan; b) Desain, merancang jaringan dalam skala waktu tertentu; c) Simulasi prototype ,melakukan eksekusi penelitian (monitoring jaringan); d) Implementasi; dan e) Manajemen , pengelolaan alokasi bandwidth jaringan yang dilakukan administrator (KURNIAWAN et al., 2018). 
I N F ORM A T I K

Jurnal Informatika, Manajemen dan Komputer, Vol. 13, No. 1 , Mei 2021

eISSN : 2580-3042

pISSN : 1979-0694

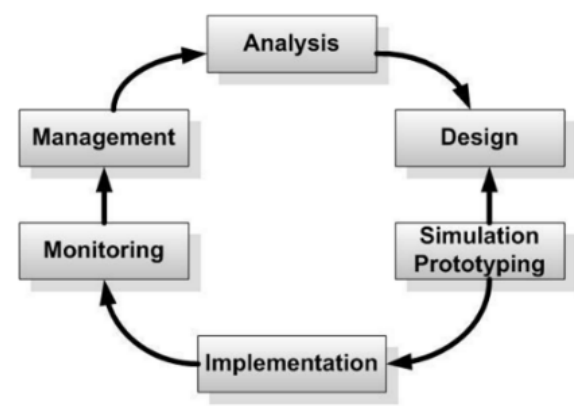

Gambar 3. Siklus NDLC

\section{g. .Analisa Masalah}

Peneliti melakukan identifikasi masalah di lingkungan Desa Geringging Baru yaitu desa tersebut mengalami kesulitan belum adanya jaringan internet yang masuk de desa tersebut, sinyal pada jaringan selular juga belum optimal. Media pembelajaran online pun belum bisa digunakan dengan baik serta melakukan penjualan hasil usaha berbasis online juga belum bisa dilakukan. Letak geografis dan kondisi di lapangan yang berbukit-bukit dan pohon-pohon tinggi tidak memungkinkan jaringan internet telekomunikasi belum masuk ke desa tersebut, Dari masalah ini peneliti melakukan penelitian perancangan infrastruktur menggunakan wireless ke desa tersebut.

\section{h. Analisa Kebutuhan}

Peneliti melakukan identifikasi berdasarkan kebutuhan dalam merancang infrastruktur jaringan RTRW.NET dari central server ke desa Geringging Baru sebagai berikut:

1. Infrastruktur yang dibangun akan mengkoneksikan jaringan internet dari central server ke Desa Geringging Baru dengan jarak $8 \mathrm{~km}$ antar antena

2. Central Server berpusat pada Universitas Islam Kuantan Singingi (UNIKS) dan akan memantau jaringan dari UNIKS

3. Manajemen bandwith yang dilakukan central server

4. Melakukan Web filter pada jaringan internet yang diberikan ke desa Geringging Baru untuk Internet Sehat.

Selanjutnya peneliti melakukan identifikasi kebutuhan berdasarkan alat-alat yang akan digunakan pada infrastruktur jaringan RTRW.NET.

Analisa Jarak / Ponting

Berdasarkan hasil observasi peneliti mendapatkan jarak antara central server dengan lokasi desa yaitu 8 kilometer, jarang ini dihitung menggunakan Aplikasi Online AirLink lengkap dengan yang menghalangi akses komunikasi dan tinggi yang direkomendasikan untuk tower seperti gambar dibawah ini:

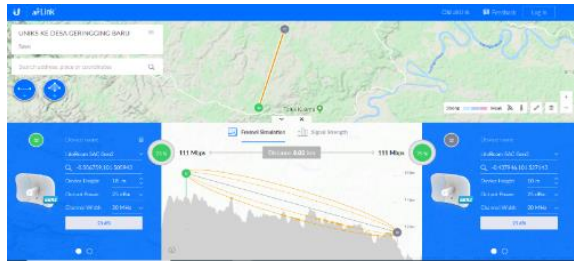

Gambar 4. Jarak ponting dari central serverke

Desa Gringging Baru menggunakan airLink Dari aplikasi airLink ini dapat di lihat ketinggian dataran central server lebih tinggi dari desa tujuan tetapi ada juga rintangan seperti perpohonan yang dapat mengganggu sinyal, agar frekuensi aman dari rintangan tersebut ketinggian antena yg diletakan pada tower central server baiknya 16 meter dari permukaan bumi dan pada balaidesa geringging baru dibuat tower setinggi 12 meter untuk antena penerima signal dan pemancar antena omni, sinyal yang didapatkan sebesar $75 \%$ dengan kecepatan komunikasi data $111 \mathrm{Mbps}$ dengan jarak pointing 8.02 kilometer. Sinyal yang didapatkan $-64 \mathrm{dBm}$ dengan output power $25 \mathrm{dBm}$ dan di channel $20 \mathrm{MHz}$.

\section{i. Design}

Pada tahap sistem ini desain topologi menggunakan peer to peer (PTP) dari central server menuju Desa Geringging baru, Pada antena central server akan di setting dengan mode access Point (Source Network) selanjutnya pada antenanya di balai desa geringging baru menggunakan mode client (Domain Network) penerima sinyal dari pengirim dari sinyal penerima tersebut kemudian dialirkan ke antena omni sebagai access Point dengan daya sebar 360" dengan jarak 1kilometer sehingga masyarakat dapat menggunakan internet tanpa kabel cukup menggunakan wireless/wifi selanjutnya antena omni tersebut akan di setting IP share static sehingga nantinya penggunaan internet ini harus didata dulu oleh kepala desa untuk menjamin penggunaan internet yang sehat.

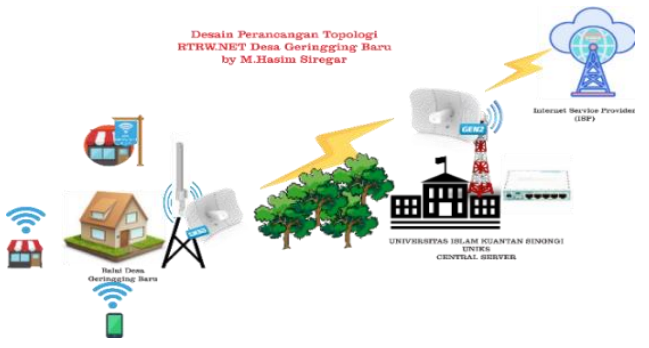

Gambar 5. Perancangan Topologi RTRW.NET 
I N F ORM A T I K

Jurnal Informatika, Manajemen dan Komputer, Vol. 13, No. 1 , Mei 2021

elSSN : 2580-3042

pISSN : 1979-0694

\section{j. Simulation dan protoype}

Pada tahapan ini berisi rincian pekerjaan, biaya dan konfigurasi perangkat jaringan yang digunakan dengan rincian sebagai berikut :

TABEL 1

RAB DAN KONFIGURASI ROUTING TABLE

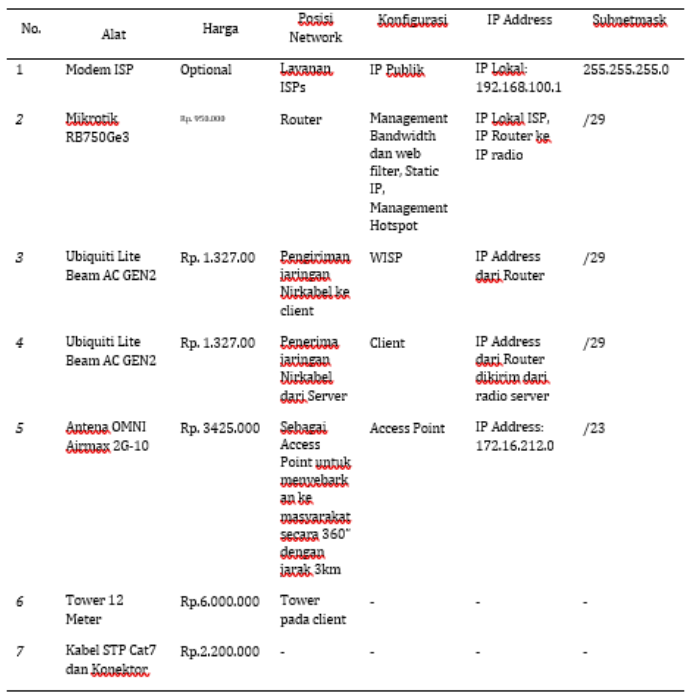

TABEL 2

ESTIMASI WAKTU PENGERJAAN PROYEK

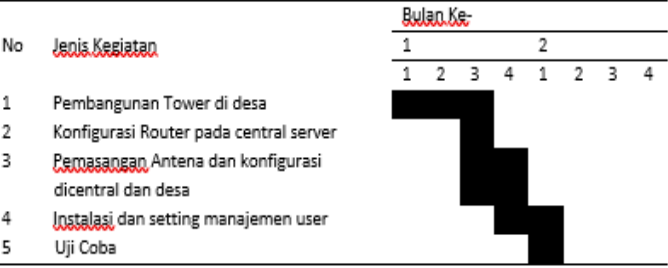

\section{HASIL DAN PEMBAHASAN}

a. Tower dan Antena

Perancangan Ketinggan tower untuk letak dari antena antara central server dan Desa Geringging Baru dilakukan dengan cara menggunakan aplikasi online "airLink" melakukan simulasi jarak dari kedua titik tersebut dan rintangan yang ada sehingga didapatkan hasilnya jarak antara kedua antena, ketinggian antena yang diletakkan, arah antena dan kekuatan sinyal pada antena.

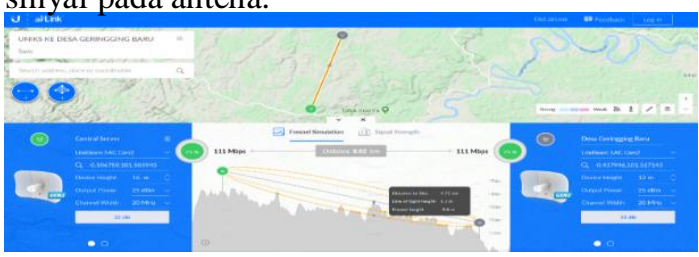

Gambar 6. Simulasi Jaringan Dari central ke Desa Geringging

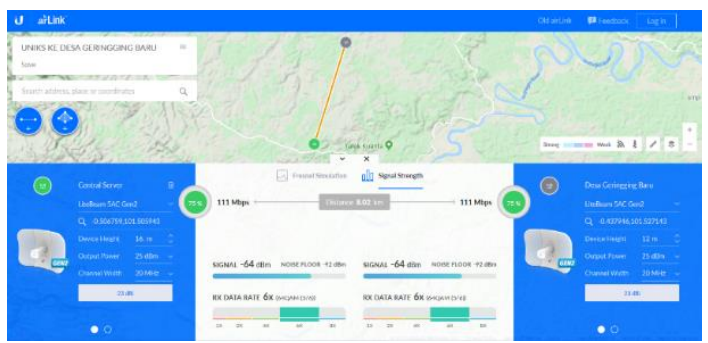

Gambar 7. Simulasi Kekuatan sinyal

Dari hasil uji coba menggunakan aplikasi simulasi online ini, pada central server menggunakan antena merk ubiquiti tipe LiteBeam 5AC Gen2 dengan letak geografi $0.506759,101.505943$ selanjutnya untuk ketinggian antena disarankan 16 meter dari permukaan tanah pada lokasi central server, ketinggian antena dan tower tersebut masih dibawah batas normal (24meter) yang ditetapkan pemerintah, untuk memaksimalkan bandwidth sampai ke tujuan dengan kecepatan 111Mbps output power yang disarankan menggunakan output power : $25 \mathrm{dbm}$. Bisa diturunkan tetapi ketika sinyal sampai ke tujuan dibawah nilai maksimal 111Mbps dengan kekuatan sinyal $75 \%$ atau signal $-64 \mathrm{dBm}$ dengan RX Data Rate 6x. Pada jarak sekitar 4.7 Kilometer ada rintangan yang hampir mengganggu Ketinggian Garis Pandang dengan jarak 1.1 meter, ini dapat diatasi dengan menaikan ketinggian antena. Pada desa Geringging Baru juga menggunakan antena merk ubiquiti tipe LiteBeam 5AC Gen2 dengan harga yang terjangkau dan letak geografi $0.437946,101.527143 \quad$ selanjutnya untuk ketinggian antena disarankan 12 meter dari permukaan tanah, untuk selanjutnya sama dengan antena pada central server dari sini transfer data dan bandwidth bebas dari gangguan sehingga bias maksimal. Pada tower di desa geringging jaya akan di tambahkan antena omni 360" guna menyebarkan sinyal wifi kepada masyarakat sekitar sehingga dapat di akses melalui perangkat smartphone maupun komputer/laptop.

\section{b. Alur Koneksivitas}

Pada awal alur perancangan infrastruktur, ISP memberikan IP Publik yang kemudian diteruskan ke Modem ISP untuk dapat keneksi ke internet, selanjutnya pada modem di setting ip 
IN F ORM A T IK A

Jurnal Informatika, Manajemen dan Komputer, Vol. 13, No. 1 , Mei 2021

eISSN : 2580-3042

pISSN : 1979-0694

private untuk ke lokal jaringan dengan IP Address 192.168.100.254 sebagai Gateway dari jaringan lokal ke Internet. Kemudian dari modem ISP dihubungkan ke Router Mikrotik menggunakan kabel UTP Cat6. Pada Router MikroTik di konfigurasi mulai dari setting Ip Network untuk ke desa geringging baru, manajemen bandwidth, Web filter dan Manajemen User, pada jaringan local untuk ke desa geringging diberi network 172.16.0.1/23 dengan subnet mask 255.255.254.0 dengan jumlah 510 host. Ip pada mikrotik tersebut dijadikan gateway untuk jaringan di desa geringging baru. Selanjutnya mikrotik dihubungkan dengan kabel utp cat6 ke antena pengirim sinyal yang disetting mode access point, sinyal dikirim melalui jaringan nirkabel (wireless) ke antena penerima yang ada di desa geringging dengan jarak 8 kilometer, kemudian sinyal diterima oleh oleh antena penerima yang disetting mode client, setelah sinyal diterima dengan baik antena penerima dihubungkan dengan antena omni menggunakan kabel utp cat 6, antena omni ini yang akan menyebarkan jaringan internet ke masyarakat tanpa menggunakan kabel yang nantinya bisa digunakan melalui smartphone dan laptop/komputer.

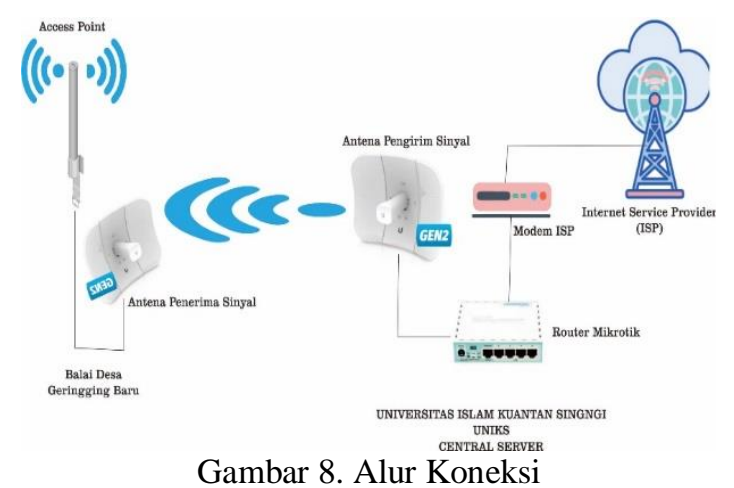

\section{KESIMPULAN}

Dari Penelitian Perancangan Infrastruktur Jaringan RTRW.NET Desa Gringing Baru Dengan Central Server Universitas Islam Kuantan Singingi dapat disimpulkan sebagai berikut: Penelitian ini dapat digunakan sebagai pedoman pada program pengabdian kepada masyarakat (PKM) baik mandiri maupun hibah

dari pemerintah dan universitas dalam membangun infrastruktur jaringan internet desa, guna pemerataan jaringan internet murah dan bisa digunakan Bersama. Dari hasil penelitian yang bersifat rancangan atau arsitektur dapat diterapkan didesa geringging baru maupun daerah lainnya yang belum ada jaringan internet ataupun derah yang terkendala sinyal dari ISPs dan Agar dapat tercapainya pemerataan infrastruktur jaringan internet murah dan stabil yang luas di seluruh pedalaman sehingga dapat memudahkan masyarakat untuk memperoleh informasi melalui internet dan menuju masyarakat yang unggul.

\section{REFERENSI}

Darmawan, D., \& Marlinda, L. (2015). Implementasi Jaringan Wireless Outdoor. Teknik Komputer Jaringan, I(2), 253-259.

KURNIAWAN, M. T., NURFAJAR, A., DWI, O., \& YUNAN, U. (2018). Desain Topologi Jaringan Kabel Nirkabel PDIILIPI dengan Cisco Three-Layered Hierarchical menggunakan NDLC. ELKOMIKA: Jurnal Teknik Energi Elektrik, Teknik Telekomunikasi, \& Teknik Elektronika, $4(1), 47$. https://doi.org/10.26760/elkomika.v4i1.47

Nurcahya, E. D., \& Internet, K. (2020). MEMBANGUN LAYANAN KAMPUNG INTERNET SEBAGAI ALTERNATIF. 10, 449-454.

Pratama, A. A., Susilo, B., \& Coastera, F. F. (2018). Manajemen Bandwidth Dengan Queue Tree Pada Rt / Rw-Net Menggunakan Mikrotik. Rekursif, 6(2), 3142.

https://ejournal.unib.ac.id/index.php/rekursi f/article/view/5513

Sumardi, S., \& Zaen, M. T. A. (2018). Perancangan Jaringan Komputer Berbasis Mikrotik Router OS Pada SMAN 4 Praya. Jurnal Informatika Dan Rekayasa Elektronik, $1(1), \quad 50$. https://doi.org/10.36595/jire.v1i1.32

Sururi, N. (2018). Menentukan Titik Pemasangan Radio Wireless untuk Link Point to Point Dengan memanfaatkan Bot Telegram. 9, 74-85. 